\title{
The "exotic" nature of ideophones - from Khoekhoe to Xhosa
}

\author{
Alexander Andrason \\ Department of African Languages, Stellenbosch University, South Africa \\ E-mail: andrason@sun.ac.za
}

\begin{abstract}
The present paper analyzes the exoticness of Khoekhoe-sourced ideophones as a possible factor that stimulated the introduction of certain phonological novelties to the sound system of Xhosa. Having analyzed Khoekhoe-sourced ideophones of Xhosa for five exotic features postulated crosslinguistically (aberrant sounds and configurations of sounds, length, tones and harmony), the author concludes the following: due to their intense phonological exoticness and the crosslinguistic propensity for unaltered borrowing, Khoekhoe-sourced ideophones may have played a relevant role in the Khoekhoe-Xhosa transfer. The efficiency of this transfer seems to be correlated with the frequency of a given exotic feature in the donor Khoekhoe lexemes.
\end{abstract}

Keywords: Khoekhoe; Xhosa; Ideophones; language contact

\section{Background}

Ideophones tend to constitute an open and productive word class in languages in which they are found (Childs 1994). ${ }^{1}$ Therefore, despite their incompatibility with derivational affixes that otherwise operate in a language (Dingemanse 2012), ${ }^{2}$ the number of ideophones may usually (and easily) be expanded. This expansion proceeds by applying expressive, iconic, and analogical mechanisms typical of ideophony crosslinguistically and/or language-specifically (Dingemanse 2014). One of such mechanisms consists of drawing ideophones from the material that is external to a particular linguistic system. Simply put - some ideophones emerge due to language contact (Childs 1989).

The role of contact-induced ideophones in a language-to-language transfer may be highly relevant. Such ideophones can contribute to the introduction of phonological material that was, at least originally, foreign to the recipient system (Lickey 1985; Childs 2003; Bostoen and Sands 2012). This stems from the markedness and/or 'exoticness' of ideophones, in general, and their status as 'phonological rebels' (Kunene 2001: 183). That is, because of their sound

\footnotetext{
${ }^{1}$ Consider for instance genetically unrelated and geographically distant languages such as Ewe (Ameka 2001: 29), Nigerian Pidgin (Faraclas 1996: 56), Urarina (Olawsky 2006: 83), Bengali (Rácová 2014: 1), and Polish (Andrason forthcoming (a)).

${ }^{2}$ Observe that ideophones typically constitute roots (Rubino 2001) and are not derived from other lexical classes (Msimang and Poulos 2001).
} 
symbolism and iconicity, ideophones often exhibit phonology that is 'anomalous' when compared to the other parts of a language (Voeltz and Killan-Hatz 2001: 2; Childs 2003: 192; Dingemanse 2012: 655-656; Lahti, Barrett and Webster 2014: 335). ${ }^{3}$ Therefore, if formed with the grammatical material extracted from another language, ideophones are more likely to carry the exotic, source phonology to the recipient system than any other loanword. This occurs especially if the transferred component coincides with the universal (i.e. crosslinguistically pervasive) phonological characteristics of ideophones (see Section 3). If this type of transfer involves a larger number of lexemes and if it is successful (i.e. the lexemes are transferred unaltered), foreign phonological features may be introduced to the recipient system permanently. ${ }^{4}$

It has been widely recognized that Xhosa experienced an intense influence of Khoekhoe languages (Louw 1974, 1976, 2013; Herbert 1990a) - specifically, a southern-eastern Khoekhoe dialect (or dialects) related to Nama and Korana (Louw 1974: 46, 51). ${ }^{5}$ This influence mainly concerned lexicon (Louw 1976; Traill 1995: 3) and phonology (Louw 1974, 1977, 2013). With respect to lexicon, at least a third part of the vocabulary of Xhosa may, in some aspect, have their roots in Khoekhoe (Louw 1976: 87). As for phonology, the contact with Khoekhoe is responsible for the presence of clicks (Harinck 1969: 150; Louw 1974: 48, 1977, 2013; Traill 1995: 3; Herbert 1990a: 296, 1990b; Vossen 1997) ${ }^{6}$ and the overall increase in the phoneme inventories of the Xhosa language (Herbert 1990a: 299). The Khoekhoe influence furthermore pertained to the "articulatory mode" of Xhosa - e.g. the use of glottalic/ejective consonants and aspirates - and the expansion of the syllabic nasal $m$ (Herbert 1990a: 301; Louw 2013) ${ }^{7}$

Given the intense linguistic transfer from Khoekhoe to Xhosa, and the above-mentioned openness of the category of ideophones that allows for drawing ideophones from other languages, it is not surprising that some ideophones found currently in Xhosa most likely had their origin outside the Xhosa language itself. They would instead have arisen through the contact of Xhosa speakers with speakers of Khoekhoe languages (Louw 1976: 7; Lickey 1985; Herbert 1990a, 1990b). ${ }^{8}$ It has been postulated that such Khoekhoe-sourced ideophones may have importantly contributed to the modification of the original sound system of Xhosa, being

\footnotetext{
${ }^{3}$ The terms 'rebel(s)', 'exotic(ness)', 'aberrant / aberrancy', and 'anomalous' will be used to refer to the broadly understood distinctiveness of ideophones if compared to the other word classes, types of lexemes, or grammatical categories. This distinctiveness may be observed and analyzed from a typological perspective and/or a languagespecific perspective. That is, across languages, ideophones tend to exhibit properties that are different from the other crosslinguistic taxa. Similarly, in a concrete language, ideophones behave in a manner distinguishing them from the other components of the grammar.

${ }^{4}$ Note, for instance, the relevance of sound symbolism in the propagation of clicks in Fwe (Bostoen and Sands 2012). The role of ideophones in the transfer may also be related to the sociolinguistic relevance of ideophones, in particular their use as expressions of local identity (Childs 2003: 121).

${ }^{5}$ Although the impact of Khoekhoe was profound, Xhosa still exhibits an unmistakable Bantu character (Louw 1976: 87). For a more critical view on the Khoe(khoe) influence on Bantu consult Du Plessis (forthcoming) according to whom the hypothesis of an intense transfer from Khoisan into Nguni is not supported by strong evidence.

${ }^{6}$ Some other Bantu languages, e.g. Southern and Northern Sotho, Tswana and Yeyi have experienced a similar influence (Childs 2003; Maddieson 2003; Clements and Rialland 2008: 63; Louw 2013). Although the Khoe(khoe) origin of clicks in Bantu is commonly recognized (Childs 2003), the exact (sociolinguistic) process through which clicks were introduced, is still debated (Herbert 1990; Childs 2003: 190).

${ }^{7}$ Albeit to a significantly lesser degree, contact with Khoekhoe also influenced the morphology of Xhosa (Louw 1976, 1986, 2013). For instance, certain suffixes may have had their origin in Khoekhoe (Louw 1976).

${ }^{8}$ It should be noted that ideophones are a common feature of Khoisan languages.
} 
responsible for (some of) its phonological novelties (Louw 1962; Lickey 1985; Childs 2003: 192; contra Herbert 1990a: 311).

The present paper deals with Xhosa ideophones that may have been induced through contact with Khoekhoe and the extent of their phonological exoticness as a possible factor in the modification of the original sound system of Xhosa. Specifically, after listing the most probable Khoekhoe-sourced ideophones of Xhosa (Section 2), I will analyze to what extent (both qualitatively and quantitatively) such lexemes exhibit features that typologically distinguish the phonology of ideophones from the phonology of other lexical and word classes (Section 3). This analysis will reveal if the class of Khoekhoe-sourced ideophones could be regarded as possibly responsible for introducing certain originally exotic features to the phonetic system of Xhosa, as hypothesized by some scholars (Section 4).

\section{Data}

There are, at least, eighteen Xhosa ideophones that most likely had their roots in Khoekhoe. All these cases have been selected from a review of the literature dedicated to the issue of Khoekhoe-sourced ideophony in Xhosa (especially Louw 1974, 1976, 2013; and Lickey 1985), as well as by examining the nearly 1900 ideophones listed in the Great Dictionary of isiXhosa (Pahl 1989; Mini 2003; Tshabe 2006). In this section, I present all such ideophones - and their possible Khoekhoe sources (or equivalents) - in an alphabetical order. ${ }^{9}$

(1) (ukuthi) cilikithi 'rush out unexpectedly, rise up suddenly' - compare with Kh(oe) $\mid$ khiri 'run or rush past goal' (Louw 1974: 49).

(2) (ukuthi) cithi 'coming out, rising suddenly into sight' - compare with Kh. $\mid k h \bar{l}$ 'come out, rise out, sprout' (Weakley 1973; Louw 1974: 52).

(3) (ukuthi) cubhu 'feeling lazy, lethargic' - compare with Kh. lowe 'feeling lazy' (Louw 1974: 60; cf. Tshabe 2006: 325).

(4) (ukuthi) cum 'break into small pieces, crumble (tr./intr.); fall into a deep sleep' compare with Kh. |hom 'thresh wheat' (Louw 1974: 50; Tshabe 2006: 328-329).

(5) (ukuthi) cwe 'be full (to the brim)' - compare with Kh. $\mid$ oa 'be full' (Louw 1974: 58; Tshabe 2006: 335-336).

(6) (ukuthi) gu 'mislead' - compare with Kh. gau 'hide oneself' (Louw 1974: 57, 1976: 93; cf. Gxowa 1994: 32, 49).

(7) (ukuthi) gxaa 'step (up) smartly, quickly; pay a hasty visit' - compare with Kh. $\| g \bar{a}$ 'fall on enemy, attack' (Louw 1974: 51; Tshabe 2006: 686).

\footnotetext{
${ }^{9}$ Each Xhosa ideophone on the list emerged by adapting a historical ancestor of the respective Khoekhoe example that was used in a Khoekhoe variety (or varieties) with which Xhosa speakers interacted. Following the original sources (Louw 1974, 1976; Pahl 1989; Mini 2003; Tshabe 2006), all the examples are from Nama.
} 
(8) (ukuthi) krwaqa 'scratch with point of spear' - compare with Kh. xoa 'scratch' (Louw 1974: 58). See also a reduplicated variant krwaqa-krwaqa' clatter with the hooves when walking or running over a stone surface’ (Mini 2003: 164).

(9) (ukuthi) $n c a$ 'adhere, stick to; lie or stand close to, lean against; be inseparable, join in with' - compare with Kh. *nca 'stick to' (Mini 2003: 441).

(10) (ukuthi) ncam 'fit exactly, be exactly alike; be satisfactory, pleasant' - compare with Kh. \|nam love (Mini 2003: 443).

(11) (ukuthi) $n g c u$ 'sit on one's haunches, be perched on top of something; place something on top of something high' - compare with Kh. $\neq n \hat{u}$ 'sit' (Louw 1974: 54; Mini 2003: 526).

(12) (ukuthi) ngcwa 'sweep away, clear away' - compare with Kh. $\hat{o} a$ 'sweep away dust, dirt' (Louw 1974: 59; cf. Gxowa 1994: 111, 141).

(13) (ukuthi) ngqo 'go straight forward, ahead, i.e. without turning' - compare with Kh. !hâu 'go straight across' (Louw 1974: 59; cf. Mini 2003: 565).

(14) (ukuthi) ngqu 'fall onto or strike the ground with the sound; throw something hard or firm down with a thud; knock against; reach down to the ground' - compare with Kh. !gâu 'hammer into' (Louw 1974: 59) or 'bump against' (Mini 2003: 568). ${ }^{10}$

(15) (ukuthi) nqwa 'meet with suddenly; unexpectedly' - compare with Kh. !oa 'meet with' (Louw 1974: 58; cf. Mini 2003: 738).

(16) (ukuthi) sawu 'cut with a sharp knife' - compare with Kh. sao 'mark cattle' (Louw 1974: 56).

(17) (ukuthi) xhole (and xhole xhole) 'peck, pick up'11 - compare with Kh. \|hora 'scratch like a hen' (Louw 1974: 49; cf. Pahl 1989: 588).

(18) (ukuthi) xhuza 'drag, jerk or tear person to another by hands' (Louw 1974: 58) or (ukuthi) xhuzu 'jerk; pull out' (Pahl 1989: 593) - compare with Kh. "hau 'catch by leg' (Louw 1974: 58).

\section{Analysis}

Scholars identify five main features that tend to distinguish the phonology of ideophones from the phonology of the other lexical and word classes across languages. These features involve the presence of aberrant sounds (see Section 3.1) or aberrant configurations of sounds (3.2), and the extensive use of length (3.3), sound harmony (3.4), and tonal patterns (3.5) (Childs

\footnotetext{
${ }^{10}$ Also more metaphorically: 'of wind - cease blowing; of clouds - be thick, heavy, dark and low' (Mini 2003: 568-569).

${ }^{11}$ Also more figuratively 'stab (with a pointed instrument)' (Pahl 1989: 588).
} 
2003, Dingemanse 2012). ${ }^{12}$ All such exotic features may be encompassed by the idea of "skewed" phonetics and/or phonotactics (Dingemanse 2012: 656). ${ }^{13}$

\subsection{Aberrant sounds}

Typological studies reveal that ideophones often contain vowels and consonants that are aberrant from the hosting language's perspective (Dingemanse 2012: 655).

As is evident from the previous statement, the structure of the hosting system is crucial to define a sound as aberrant. Nevertheless, some sounds are crosslinguistically more marked than others. Probably, one of the most marked classes of sounds are clicks (Herbert 1990a: 299, 1990b). Although some languages include clicks in their phonemic inventory, in many others these types of consonants are absent. However, even in languages in which clicks are generally unattested, they are found in ideophones and interjections (Herbert 1990: 311; Andrason forthcoming (a)).

Certainly, in both Khoekhoe and Xhosa, clicks are not aberrant per se. On the contrary, they constitute elements that are common in the phonetic systems of these two languages. Nevertheless, for early Nguni speakers, whose language did contain clicks, clicks must have constituted a highly exotic feature. In contemporary Xhosa, clicks appear in circa $15 \%$ of the vocabulary (Herbert 1990a: 296). Significantly, the use of clicks in ideophones in Xhosa is more common than elsewhere in the language, being found in $30 \%$ of the ideophonic lexemes (Andrason forthcoming (b)). This tendency is even more evident in Khoekhoe-sourced ideophones - a click consonant appears in sixteen of the eighteen ideophones that derive from Khoekhoe, which equals more than $80 \% .{ }^{14}$ In agreement with the general rule governing the Khoekhoe-Xhosa transfer of clicks, the dental [l], the post-alveolar [!], and the lateral alveolar [II] clicks of Khoekhoe are usually preserved as such (cf. Louw 1974, 2013: 876, 881). Accordingly, the dental click [|] is maintained in cilikithi, cithi, cubhu, cum, cwe, and ngcwa. The post-alveolar click [!] survives in $n g q o, n g q u$, and $n q w a .{ }^{15}$ The lateral alveolar click [\|] is preserved in gxaa, xhole, and xhuza. However, in Khoekhoe-sourced ideophones, [\|] also surfaces as the dental click $c$, as illustrated by the ideophone ncam. Khoekhoe additionally possesses a palato-alveolar click [‡], which is absent in Xhosa. As is true of the general adaptation of [ ] in Xhosa, this click is resolved into $c$ in the ideophone $n g c u$ (cf. Louw 1976: 89, 2013: 882). ${ }^{16}$

Diphthongs constitute another feature that could have been viewed as exotic by early Xhosa speakers (cf. Herbert 1990a: 299). For instance, vowel clusters /ae/, /ai/, /ao/, /oa/, /oe/ and /ui/ are typical of Khoekhoe but were (and still are) absent in Xhosa. Generally, Khoekhoe diphthongs are not preserved in the Xhosa language. Rather, either one of the vowel is

\footnotetext{
${ }^{12}$ Additionally, ideophones are often accompanied by distinctive types of phonation (Dingemanse 2012).

${ }^{13}$ All such aberrant properties arise from (and contribute to) the iconicity of ideophones (i.e. ideophones are the most direct grammatical substitutes for real-world physical acts; Kunene 2001: 183) and their expressiveness and impressiveness (Dingemanse 2012: 655-656).

${ }^{14}$ Even though my sample is very limited, this persistency is unmistakable. Only two ideophones do not exhibit a click, namely gu and sawu.

${ }^{15}$ In Xhosa, this click is defined as alveo(lo)-palatal or pre-palatal.

${ }^{16}$ Furthermore, conforming to the phonetics of clicks in Xhosa, Khoekhoe-sourced ideophones may exhibit four possible manners of articulation: plain (often ejected, e.g. cum), breathy (e.g. gxaa), aspirated (e.g. xhole), and nasalized (e.g. nqwa) (cf. Herbert 1990: 296).
} 
consonantized, being realized as a glide or a semi-vowel, or the vowel cluster resolves into a monophthong (Louw 1974: 54-59, 61; Herbert 1990a). Khoekhoe-sourced ideophones show the same tendency (Louw 1974). The Khoekhoe vowel cluster loal resolves into $w V$ as illustrated by cwe (Kh. $\mid o a)$, krwaqa (Kh. xoa), and nqwa (Kh. !oa) (cf. Louw 1974: 58). The same applies to a nasalized diphthong (compare ngcwa with Kh. $\mid \hat{o} a$ ). In the ideophone sawu (Kh. sao) an intervocalic glide was inserted. Almost equally often, the diphthong - specifically lau/ - is reduced to a monophthong, either $o$ or $u$ (cf. Louw 1974: 57, 59). This may be illustrated by ideophones whose Khoekhoe sources exhibit a 'plain' diphthong ( $g u-\mathrm{Kh}$. gau; $x h u z a-$ Kh. \|hau) or a nasalized diphthong (ngqo - Kh. !hâu; ngqu - Kh. !gâu). ${ }^{17}$ Even though Khoekhoe-sourced ideophones do not preserve diphthongs or vowel clusters, it is remarkable that half of them derive from roots or stems that likely contained such sounds (compare $c w e$, gu krwaqa, ngcwa, ngqo, ngqu, nqwa, sawu, and xhuza). ${ }^{18}$

A further feature that may be regarded as exotic for the Xhosa phonetic system is nasalization of vowels, which, in contrast, characterizes Khoe(khoe) languages (Louw 1974: 47). In borrowings from Khoekhoe, nasal vowels are resolved either by transferring the nasal component from the vowel to the adjacent consonant, or by introducing a nasal segment after the vowel, typically marked by the consonant $-m$ or $-n$ (Louw 1974: 54, 61). In the Khoekhoesourced ideophones, the former of the two tendencies is regular as demonstrated by ngcu (Kh. łnû), ngcwa (Kh. $\mid \hat{a} a), n g q o(\mathrm{Kh}$. !hâu), and ngqu (Kh. !gâu).

Khoekhoe languages also include the consonant $r$ which was originally missing in Nguni and might have been perceived as exotic to Xhosa speakers. In Xhosa, Khoekhoe borrowings containing $r$ regularly surface as $l$ or $d$ (Louw 1974: 47, 1976: 88). By substituting $r$ with $l$, the Khoekhoe-sourced ideophones cilikithi (Kh. |Khiri) and xhole (Kh. \|hora) conform to this general tendency.

\subsection{Aberrant sound configurations}

Ideophones often exhibit aberrant configurations of sounds that are otherwise non-exotic in the language (Dingemanse 2012: 656). This aberrancy may concern the structure of a syllable, the presence of certain consonant clusters, or the placement of a phoneme.

In Xhosa, the last syllable of a word is typically open, hence, words tend to end in a vowel. ${ }^{19}$ In contrast, word-final consonants are a common feature of Khoekhoe. ${ }^{20}$ Given this dissimilarity, in the process of adaptation to Xhosa, Khoekhoe words ending in a consonant either eliminate that final consonant, or are extended by an additional vowel (Herbert 1990a: 299). In contrast to that general rule, Xhosa ideophones may end in a consonant. To be exact,

\footnotetext{
17 The shift $a u>o$ is also reflected within Khoekhoe itself.

${ }^{18}$ The adaptation of diphthongs through their monophthongization or consonantization need not only stem from the original internal characteristics of Xhosa. Diphthongs generally tend to behave peculiarly in contact situations as illustrated by the history of Romance languages, English varieties worldwide (Mesthrie 2010: 521-522, 524), and other contact languages (Matras 2009: 230). Nevertheless, the absence (or scarcity) of diphthongs in Xhosa (which is also a salient feature of Bantu in general; Clements 2000: 135; Mesthrie 2010: 521) might have importantly contributed to the loss of these sounds in the lexemes borrowed from Khoekhoe.

${ }^{19}$ A noticeable exception are certain pronominal forms ending in $-m$, such as yam 'my'. In these types of words, the final consonantal element is historically a clitic or suffix.

${ }^{20}$ It should be noted that most of apparent consonantal word endings are in fact gender suffixes. The only consonants that can occur at the end of a root in Khoe languages are the nasals $m$ and $n$.
} 
at least $2 \%$ of ideophones exhibit a consonant as its final element (Andrason forthcoming (b)). This consonant is typically $-m$ although other consonants (e.g. $p h, k h$, or $r$ ) are also possible (ibid.). ${ }^{21}$

In accordance with the general behavior of ideophones in Xhosa, Khoekhoe-sourced ideophones regularly preserve the final consonant $m$, as illustrated by $n c a m$ (Kh. \|nam) and $\operatorname{cum}(\text { Kh. } \mid \text { hom })^{22}$

\subsection{Length}

A crosslinguistically common distinctive feature of ideophones is their association with length. That is, ideophones often exhibit long and extra-long vowels and consonant. This includes languages in which length is not utilized at all (Dingemanse 2012: 656). Moreover, in ideophones, length may play a phonemic role, even though its phonemic implications are absent, or limited, in the other parts of the grammar.

In Khoekhoe, vowels may be long, both at a phonetic and phonemic level. This contrasts with the situation found in Xhosa, where - with a few exceptions - length is not phonemic (Pahl 1989: xxxv). Rather, vowels found in the penultimate syllable of a (phonological) word are regularly lengthened (Oosthuysen 2016). Given the limited operativeness of length in Xhosa, when an original long vowel is transferred from a Khoekhoe word to Xhosa, it surfaces as short. However, it may be lengthened if appearing in the penultimate syllable (Louw 1974: 52).

The exploitation of length is significantly richer in Xhosa ideophones. Xhosa ideophones exhibit four measures of length, containing a long, an extra-long, or an extra-extra-long vowel in addition to short vowels. In several cases, the length plays a phonemic role, distinguishing ideophones associated with different meanings. Such phonemic distinction may concern two or three length measures, or exceptionally even four (Andrason forthcoming (b)). ${ }^{23}$

In accordance with the tendency outlined in the previous paragraph, Khoekhoe-sourced ideophones may preserve an original long vowel. This is demonstrated by gxaa, in which the long vowel [a:] reflects a long vowel of the original Khoekhoe word (cf. Kh. \|gā) (Louw 1974: 52). Nevertheless, in two other cases where the source form is likely to have contained a long vowel, the corresponding Xhosa variant exhibits a short vowel: $n g c u$ versus Kh. $¥ n \hat{u}$ and cithi versus Kh. $\mid k h \bar{\imath}$.

\subsection{Tone}

The presence of tones is characteristic of ideophones in various languages. This occurs even in systems that do not include tone in their phonetic and/or phonemic inventories.

In general, tone is a common feature in Xhosa and Khoekhoe (Louw 1974, 2013, Jordan 1966, Oosthuisen 2016). In Xhosa, tone is found throughout the lexicon, often playing a phonemic role. Nevertheless, certain tonal phenomena distinguish Xhosa ideophones from the other parts

\footnotetext{
${ }^{21}$ Certain interjections and nouns derived from ideophones and onomatopoeias, as well as certain loanwords, may also exhibit final closed syllables.

${ }^{22}$ Compare the discussion of $m$ in the Khoekhoe-Xhosa transfer in Louw (2013: 879).

${ }^{23}$ See also the relevance of length in ideophones in Zulu (Van Staden 1977; cf. Johnson 1976).
} 
of the Xhosa grammar. Ideophones reveal a strong tendency for the presence of low-tone patterns, which are present in $80 \%$ of all the ideophonic lexemes (Andrason forthcoming (b)). The phonemic status of tone is likewise more visible in ideophones than elsewhere in the language, as $1 \%$ of the ideophones are distinguished by tone (ibid.).

Khoekhoe-sourced ideophones comply with these tendencies. First, most of the ideophones exhibit a low-tone pattern. This holds true for ideophones that are monosyllabic (cùm, ngqò, ngqù, nqwà), disyllabic (cìthì, xhòlè, krwàqà, xhùzù), or polysyllabic (cìlikithì). The presence of high tones is significantly less common (cwé, ngcú). Sometimes, different tones appear (gxáà and cúbhù - see however, cùbhù-cùbhù where the low tone is generalized). Second, in one case, the tone is phonemic, differentiating the Khoekhoe-sourced ideophone $c w e$ from $c w e ̀$ 'cut off a thin piece of meat or skin' (Mini 2003: 336).

\subsection{Harmony}

The last feature that distinguishes the phonology of ideophones from the phonology of the other word- and lexical classes is harmony: ideophones tend to exhibit vocalic, consonantal, and tonal harmony, creating the impression of rhymes (Dingemanse 2012: 656; Andrason forthcoming (a) and (b)).

Contrary to other lexemes, Xhosa ideophones make extensive use of vowel harmony, which may be full, partial, or imprecise. To be exact, almost 95\% of ideophones in Xhosa exhibit some type of vocalic harmony (Andrason forthcoming (b)). This phenomenon is also visible in Khoekhoe-sourced ideophones such as cilikithi (Kh. |Khiri), cithi (Kh. $\mid k h \bar{\imath})$, krwaqa (Kh. xoa), and $x h u z u$ (Kh. \|hau), which either maintained or created vocalically harmonious patterns. Especially significant is the ideophone cubhu. In this example, the original non-harmonious vowel pattern (see Kh, lowe) was reshaped to a pattern that presents vocalic harmony (cf. Louw 1974: 60). Nevertheless, non-harmonious sequences are also found as illustrated by xhole (Kh. Ihora). In this case, harmony was not introduced.

Vowels are not the only elements that can create the effect of harmony - tones may also assume such roles. In the general lexicon of Xhosa, the tone alternation is the rule, harmony being thus avoided (Jordan 1966). In contrast, the harmony of tones is pervasive in ideophones, appearing in $75 \%$ of the ideophonic lexemes (Andrason forthcoming (b)). In accordance with the tendency characterizing the category of ideophony in Xhosa, most of the Khoekhoe-sourced ideophones exhibit tonal harmony. This may be illustrated by cìlikithì, cìthì, xhòlè, krwàqà, xhùzù. A harmonious tonal structure is absent only in two examples: gxáà and cúbhù.

\section{Conclusion}

The analysis of the data demonstrates that Khoekhoe-sourced ideophones exhibit a relatively high degree of phonological exoticness. This exotic character was either inherited from Khoekhoe or developed by analogy to other Xhosa ideophones.

Khoekhoe-sourced ideophones abound in etymological (i.e. directly inhered) clicks. They also include nasal clicks, which are successors of the original combination of clicks and nasal vowels - another common feature of the Khoekhoe donor lexemes analyzed in this paper. Khoekhoesourced ideophones may exhibit a genetically accurate final closed-syllable structure and, albeit 
only sporadically, an original long vowel. Contrary to clicks and nasals, neither the final consonants nor the long vowels are particularly common in the underlying Khoekhoe lexemes. The original Khoekhoe vocabulary examined in this article also abounded in diphthongs and vowel clusters which were, however, eliminated during the transfer into the Xhosa system. Very infrequently, the underlying donor lexemes contained $r$. This was regularly adjusted to the nonexotic Xhosa $l .{ }^{24}$ Furthermore, vocalic harmony typically replaced the original Khoekhoe sequences or expanded monosyllabic donor structures. Likewise, tonal harmony - with a pervasive use of low-tone patterns - is often present in Khoekhoe-sourced ideophones. ${ }^{25}$

Consequently, the study provides support to the hypothesis that Khoekhoe-sourced ideophones - due to their markedness and exoticness - may have contributed to the modification of the original Xhosa phonology. ${ }^{26}$ The incorporation of a given exotic feature can often be correlated with its high frequency in the donor Khoekhoe lexemes.

First, exotic features that are highly common in the underlying Khoekhoe vocabulary were transferred to the sound system of Xhosa relatively efficiently. Specifically, Khoekhoe-sourced ideophones abound in clicks, as did their Khoekhoe donor lexemes. Therefore, given the tolerance of ideophones for exotic sounds, clicks could have been transferred to Xhosa unaltered. Once transferred and generalized in ideophones, they could have spread to the other parts of the language (cf. Louw 1962; Lickey 1985; Childs 2003: 192). By following an analogous process, Khoekhoe-sourced ideophones may also have enhanced the development of nasal clicks, thus increasing the phonetic inventory of the language (cf. Herbert 1990a: 299).

Second, less common exotic features such as long vowels and word-final consonants were nearly only generalized in the class of Xhosa ideophones themselves. That is, given their lesser frequency, they never spread in a more universal manner to the other parts of the language.

Third, the exotic feature that was uncommon in the donor lexemes - i.e. the presence of $r-$ failed to be introduced to the sounds system of Xhosa. ${ }^{27}$

In contrast to the above mentioned correlation between the frequency of an exotic feature and its incorporation into Xhosa, diphthongs and vowel clusters - common in the Khoekhoe input lexemes - were not carried into Xhosa. If Khoekhoe-sourced ideophones were responsible for the Khoekhoe-Xhosa transfer, the absence of diphthongs and vowel clusters is puzzling. Most likely, the dissimilar treatment of clicks and diphthongs stems from the universal markedness of the former sounds. While clicks are crosslinguistically typical of ideophones, contributing to their sound symbolism and iconicity, diphthongs are not - their potential aberrancy rather stems from the structure of the recipient system.

Lastly, the exotic patterns of vocalic and tonal harmony exhibited by the Khoekhoe-sourced ideophones seem to have been established by analogy with the general patterns that characterize

\footnotetext{
${ }^{24}$ Compare with the view according to which the absence of the transfer of the bilabial click among Khoesan languages principally stems from the low frequency of that sound in source languages (Sands 2014).

${ }^{25}$ Those two last features are pervasive characteristics of the class of ideophones in Xhosa.

${ }^{26}$ These results do not, however, rule out that other sociological and linguistic factors may also have (importantly) contributed to the modification of the sound system of Xhosa. Consider, for instance, the phenomenon of ukuhlonipha (Herbert 1990).

${ }^{27}$ The use of $r$ in contemporary Xhosa is not a Khoekhoe influence, but rather a relatively recent transfer from English.
} 
ideophones in Xhosa (and/or might have characterized it at an earlier stage of the language). In such cases, a Xhosa internal feature was introduced to the Khoekhoe-sourced ideophones, rather than vice-versa.

Although this paper corroborates the hypothesis of the significance of Khoekhoe-sourced ideophones for the introduction of novel properties to the Xhosa sound system due to their (i.e. such ideophones') exoticness or markedness, its results should be treated as preliminary. Crucially, the list of possible Khoekhoe-sourced words is brief and - even if accurate in its totality - represents only a fraction of the ideophones attested to in Xhosa. Without doubts, a larger corpus of Khoekhoe-sourced ideophones must be established such that generalizations proposed here could be rendered more reliable.

\section{References}

Andrason, A. forthcoming (a). Ideophones in Polish.

Andrason, A. forthcoming (b). Ideophones as linguistic "rebels" - evidence from Xhosa.

Ameka, F. 2001. Ideophones and the nature of the adjective word class in Ewe. In E. Voeltz and C. Kilian-Hatz (eds.) Ideophones. Amsterdam: John Benjamins. pp. 25-48.

Bostoen, K. and B. Sands. 2012. Clicks in south-western Bantu languages: Contact-induced vs. language-internal lexical change. In M. Brenzinger and A-M. Fehn (eds.) Proceedings of the 6th World Congress of African Linguistics, Cologne, 17-21 August 2009. Cologne: Rüdiger Köppe. pp. 121-132.

Childs, T. 1989. Where do ideophones come from? Studies in the Linguistic Science 19(2): 5576.

Childs, T. 1994. African ideophones. In L. Hinton, J. Nichols and J. J. Ohala (eds.) Sound Symbolism. Cambridge: Cambridge University Press. pp. 178-204.

Childs, T. 2003. An introduction to African languages. Amsterdam: John Benjamins.

Clements, G. N. 2000. Phonology. In B. Heine and D. Nurse (eds.) African languages: An introduction. Cambridge: Cambridge University Press. pp. 123-160.

Clements, G. N. and A. Rialland. 2008. Africa as a phonological area. In B. Heine and D. Nurse (eds.) A linguistic geography of Africa. Cambridge: Cambridge University Press. pp. 36-85.

Dingemanse, M. 2012. Advances in the cross-linguistic study of ideophones. Language and Linguistics Compass 6: 654-672.

Dingemanse, M. 2014. Making new ideophones in Siwu: Creative depiction in conversation. Pragmatics and Society 5(3): 355-383.

Du Plessis, M. forthcoming. Kora: A Lost Khoisan Language of the early Cape and the Gariep. Pretoria: Unisa Press \& South African History Online. 
Faraclas, N. 1996. Nigerian Pidgin. London: Routledge.

Gxowa, N. C. 1994. Ideophones in Xhosa. MA dissertation, Stellenbosch University.

Harinck, G. 1969. Interaction between Xhosa and Khoe: Emphasis on the period 1620-1750. In

L. Thompson (ed.) African societies in Southern Africa. London: Heinemann. pp. 145-169.

Herbert, R. 1990a. The sociohistory of clicks in Southern Bantu. Anthropological Linguistics 32(3/4): 295-315

Herbert, R. 1990b. The relative markedness of click sounds: Evidence from language change, acquisition, and avoidance. Anthropological Linguistics 32 (1/2): 120-138.

Johnson, M. 1976. Toward a definition of the ideophone in Bantu. Ohio State University Working Papers in Linguistics 21: 240-253.

Jordan, A. C. 1966. A practical course in Xhosa. Johannesburg: Longmans.

Kunene, D. 2001. Speaking the act: The ideophone as a linguistic rebel. In E. Voeltz and C. Kilian-Hatz (eds.) Ideophones. Amsterdam: John Benjamins. pp. 183-192.

Lahti, K., R. Barrett and A. Webster. 2014. Introduction. Pragmatics and Society 5(3) (Special Issue: Ideophones: Between Grammar and Poetry): 335-340.

Lickey, S. 1985. Khoisan influence in Southern Bantu: An investigation. MA dissertation, University of Pittsburgh.

Louw, J. A. 1962. The segmental phonemes of Zulu. Afrika und Ubersee 46: 43-93.

Louw, J. A. 1974. The influence of Khoi on the Xhosa language. Limi 2(2): 45-62.

Louw, J. A. 1976. The Influence of Khoi on Xhosa Morphology. In W. J. de Klerk and F. A. Ponelis (eds.) Gedenkbundel H. J. J. M. van der Merwe. Pretoria: J. L. van Schaik. pp. 87-95

Louw, J. A. 1977. Click as loans in Xhosa. In J. Snyman (ed.) Bushman and Hottentot linguistic studies 1975. Pretoria: UNISA. pp. 82-100.

Louw, J. A. 1986. Some linguistic influence of Khoi and San in the prehistory of the Nguni. In R. Vossen and K. Keuthmann (eds.) Contemporary studies in Khoisan 2. Hamburg: Helmut Buske. pp. 141-168.

Louw, J. A. 2013. The impact of Khoesan on southern Bantu. In R. Vosser (ed.) The Khoesan languages. London: Routledge. pp. 435-444.

Maddieson, I. 2003. The sounds of the Bantu languages. In D. Nurse and G. Philippson (eds.) The Bantu languages. London: Routledge. pp. 15-41.

Matras, Y. 2009. Language contact. Cambridge: Cambridge University Press. 
Mesthrie, R. 2010. Contact and African Englishes. In R. Hickey (ed.) The handbook of language contact. Malden: Wiley-Blackwell. pp. 518-537.

Mini, B. M. (ed.) 2003. The greater dictionary of isiXhosa. Vol 2. Fort Hare: University of Fort Hare.

Msimang, C. T. and G. Poulos. 2001. The ideophone in Zulu: A re-examination of conceptual and descriptive notions. In E. Voeltz and C. Kilian-Hatz (eds.) Ideophones. Amsterdam: John Benjamins. pp. 235-250.

Olawsky, K. 2006. A grammar of Urarina. Berlin: Mouton de Gruyter.

Oosthuysen, J. C. 2016. The grammar of isiXhosa. Stellenbosch: Sun Media.

Pahl, H. W. (ed.) 1989. The greater dictionary of isiXhosa. Vol 3. Fort Hare: University of Fort Hare.

Rácová, A. 2014. Ideophones in Bengali. Asian and African Studies 23(1): 1-36.

Rubino, C. 2001. Iconic morphology and word formation in Ilocano. In E. Voeltz and C. KilianHatz (eds.) Ideophones. Amsterdam: John Benjamins. pp. 303-320.

Sands, B. 2014. Adoption, maintenance and loss of click contrasts. Sound Change in Interacting Human Systems, $3^{\text {rd }}$ Biennial Workshop on Sound Change, University of California, Berkeley, May 28-31, 2014.

Traill, A. 1995. The Khoesan languages of South Africa. In R. Mesthrie (ed.) Language and social history. Studies in South African sociolinguistics. Cape Town: David Philip. pp. 1-18.

Tshabe, S. L. (ed.) 2006. The greater dictionary of isiXhosa. Vol 1. Fort Hare: University of Fort Hare.

Van Staden, P. 1977. Some Remarks on Ideophones in Zulu. African Studies 36(2): 195-224.

Voeltz, E. and C. Kilian-Hatz. 2001. Introduction. In E. Voeltz and C. Kilian-Hatz (eds.), Ideophones. Amsterdam: John Benjamins. pp. 1-9.

Vossen, R. 1997. What click sounds got to do in Bantu. Reconstructing the history of language contacts in southern Africa. In B. Smieja and M. Tasch (eds.) Human contact through language and linguistics. Frankfurt am Main: Peter Lang. pp. 353-366.

Weakley, A. J. 1973. An introduction to Xhosa ideophone derivation and syntax. Grahamstown: Rhodes University, Department of African Languages. (Communications 2). 